\title{
Application of machine learning in ophthalmic imaging modalities
}

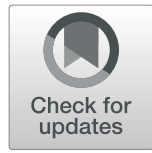

Yan Tong ${ }^{1}$, Wei Lu', Yue Yu' and Yin Shen ${ }^{1,2^{*}}$

\begin{abstract}
In clinical ophthalmology, a variety of image-related diagnostic techniques have begun to offer unprecedented insights into eye diseases based on morphological datasets with millions of data points. Artificial intelligence (Al), inspired by the human multilayered neuronal system, has shown astonishing success within some visual and auditory recognition tasks. In these tasks, Al can analyze digital data in a comprehensive, rapid and non-invasive manner. Bioinformatics has become a focus particularly in the field of medical imaging, where it is driven by enhanced computing power and cloud storage, as well as utilization of novel algorithms and generation of data in massive quantities. Machine learning (ML) is an important branch in the field of Al. The overall potential of $\mathrm{ML}$ to automatically pinpoint, identify and grade pathological features in ocular diseases will empower ophthalmologists to provide high-quality diagnosis and facilitate personalized health care in the near future. This review offers perspectives on the origin, development, and applications of ML technology, particularly regarding its applications in ophthalmic imaging modalities.
\end{abstract}

Keywords: Artificial intelligence, Deep learning, Ophthalmic imaging modalities, Machine learning

\section{Background}

Medical imaging is important in clinical diagnosis and individualized treatment of eye diseases [1-3]. This technology can provide high-resolution information regarding anatomic and functional changes. In recent years, imaging techniques have developed rapidly, together with therapeutic advances [4]. However, with the increasing sophistication of imaging technology, comprehension and management of eye disease has become more complex due to the large numbers of images and findings that can be recorded for individual patients, as well as the hypotheses supported by these data. Thus, each patient has become a "big data" challenge [5].

Conventional diagnostic methods greatly depend on physicians' professional experience and knowledge, which can lead to a high rate of misdiagnosis and

\footnotetext{
* Correspondence: yinshen@whu.edu.cn

${ }^{1}$ Eye Center, Renmin Hospital of Wuhan University, Wuhan 430060, Hubei, China

${ }^{2}$ Medical Research Institute, Wuhan University, Wuhan, Hubei, China
}

wastage of medical data [6]. The new era of clinical diagnostics and therapeutics urgently requires intelligent tools to manage medical data safely and efficiently. Artificial intelligence (AI) has been widely applied across various contexts in medicine (Fig. 1). In particular, collaborations between medical imaging and AI disciplines have proven highly productive in the fields of radiology, dermatology and pathology [7].

AI has improved the performance of many challenging tasks in medical imaging, such as diagnosis of cutaneous malignancies using skin photographs [8], detection of lung cancer using chest images [9], prediction of cardiovascular disease risk using computer tomographic (CT) [10], detection of pulmonary embolism using CT angiography [11], analysis of breast histopathology using tissue sections [12], detection of polyps using virtual colonoscopy [13], diagnosis of glioma using magnetic resonance imaging (MRI) [14], and diagnosis of neurological disease using functional MRI (e.g., Alzheimer's disease) [15-17]. Furthermore, AI has a considerable impact in 


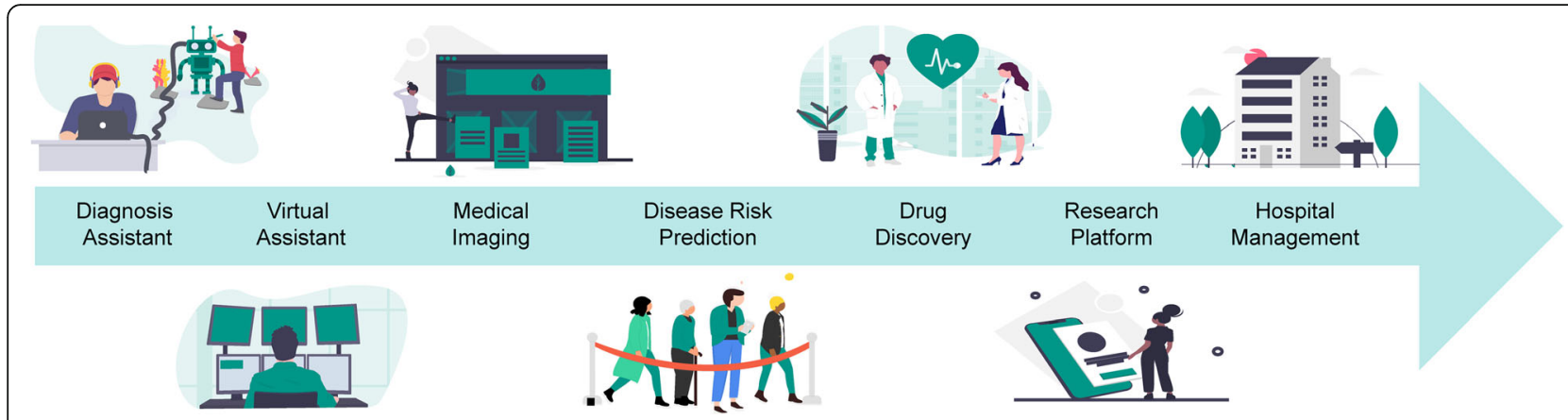

Fig. 1 The applications of Al techniques in the eye clinic

ophthalmology, mainly through accurate and efficient image interpretation [18].

The rapid increase in AI requires ophthalmologists to embrace intelligent algorithms and gain a greater understanding of the abilities of the technology, and thus enable them to evaluate and apply AI in a constructive manner. Here, we comprehensively reviewed the general applications of ML technology in ophthalmic imaging modalities, including the three most commonly used methods: fundus photography (FP), optical coherence tomography (OCT) and slit-lamp imaging. Throughout the review, we introduce basic definitions of terms commonly used when discussing ML applications, as well as the workflow for building AI models and an overview of the balance between the challenges and opportunities for ML technology in ophthalmic imaging.

\section{Main text}

\section{From machine learning (ML) to deep learning (DL)}

AI refers to the field of computer science that mimics human cognitive function [19]. ML is a subfield of AI that allows computers to learn from a set of data and subsequently make predictions; these processes can be classified as supervised and unsupervised learning.

In supervised learning, a machine is trained with input data previously labeled by humans to predict the desired outcome such that it can solve classification and regression problems. However, this approach is timeconsuming because it requires a considerable amount of data to be labeled manually. Conversely, in unsupervised learning, a machine is provided input data that are not explicitly labeled; the machine is then permitted to identify structures and patterns from the set of objects, without human influence. Conventional ML algorithms include decision tree [20], naive Bayes algorithm [21], random forest (RF) [22], support vector machine (SVM) [23, 24], k-nearest neighbor (KNN) [25] (Table 1). Despite obtaining good performance with small datasets, ML network architecture makes them more prone to fail in reaching the convergence and overfitting training dataset because of manual features selection process, which limits their application.

Among the techniques comprising ML, one of the most promising is DL (Fig. 2) [26]. This mimics the operation of the human brain using multiple layers of artificial neural networks that can generate automated predictions from input data. DL currently has central roles in various tasks, including image recognition (e.g., facial recognition in Facebook, image search in Google), virtual assistant (e.g., Apple's Siri, Amazon's Alexa, and Microsoft's Cortana), and diagnostic assistant systems (e.g. IBM Watson for Oncology). Representative DL

Table 1 Representative algorithms in $\mathrm{ML}$ and $\mathrm{DL}$

\begin{tabular}{lll}
\hline Al Techniques & Classification & Algorithms \\
\hline Conventional Machine learning & Supervised learning & $\begin{array}{l}\text { SVM, Linear Regression, Logistic Regression, RF, KNN, Naïve Bayesian, Decision Tree, } \\
\text { AdaBoost, Neural network methods }\end{array}$ \\
& Unsupervised learning & $\begin{array}{l}\text { Principal component analysis, K-means, Expectation-maximization, Mean shift, Hierarchical } \\
\text { clustering, Affinity propagation, Iterative self-organizing data, fuzzy C-means systems }\end{array}$ \\
Reinforcement learning learning & $\begin{array}{l}\text { Q-learning, Temporal difference learning, State-Action-Reward-State-Action, Teaching-Box } \\
\text { systems, Maja systems } \\
\text { Convolutional deep belief network, Conditional restricted Boltzmann machine }\end{array}$ \\
CNN & $\begin{array}{l}\text { AlexNet, GoogleNet, Visual geometry group network (VGG), Deep Residual Learning, } \\
\text { Inception v4 (V2, V3), Restnet-152 (34,50,101), LeNet } \\
\text { Bidirectional RNN, Long short-term memory }\end{array}$ \\
\hline
\end{tabular}




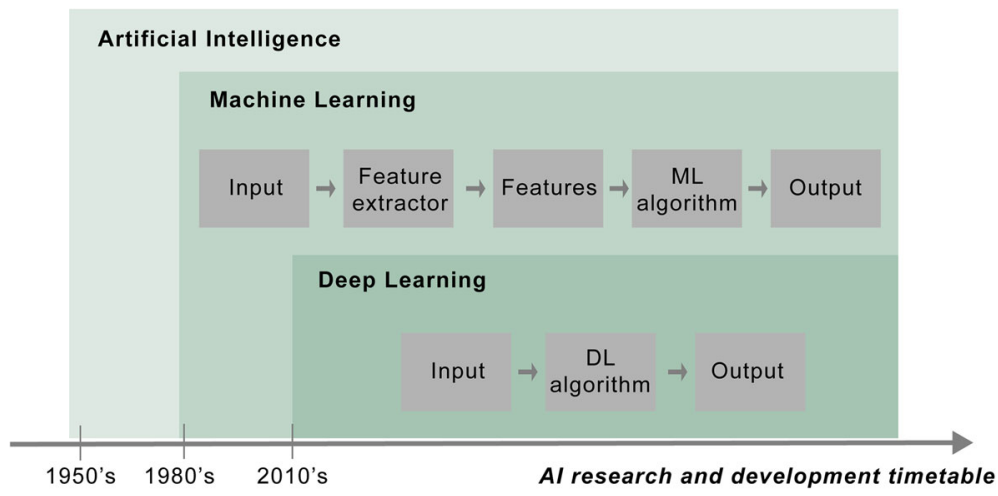

Fig. 2 The relationship among the subsets of Al. Machine learning techniques occurred in the 1980s, while deep learning techniques has been applied since the 2010s. Abbreviations: ML, machine learning; DL, deep learning

algorithms are deep belief network (DBN) [27, 28], convolution neural network $(\mathrm{CNN})$ [29], recurrent neural network (RNN) [30, 31] (Table 1). Compared with conventional $\mathrm{ML}$, the architecture of $\mathrm{DL}$ uses more hidden layers to decode image raw data without the need to handcraft specific features or use feature selection algorithm, which has the advantage of efficiency and can explore more complex non-linear pattern in the data (Fig. 2).

Visual representation of some common algorithms in ML and DL is shown in Fig. 3. The most commonly applied algorithm in image recognition is CNN. Existing $\mathrm{CNN}$ architectures that have been the most widely used include LeNet [32], AlexNet [33], ResNet [34], a

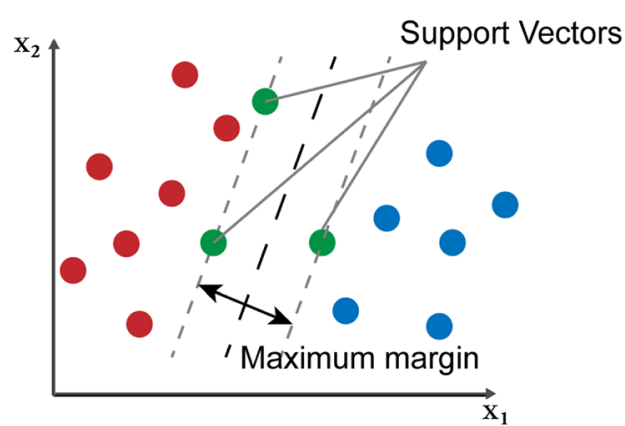

C

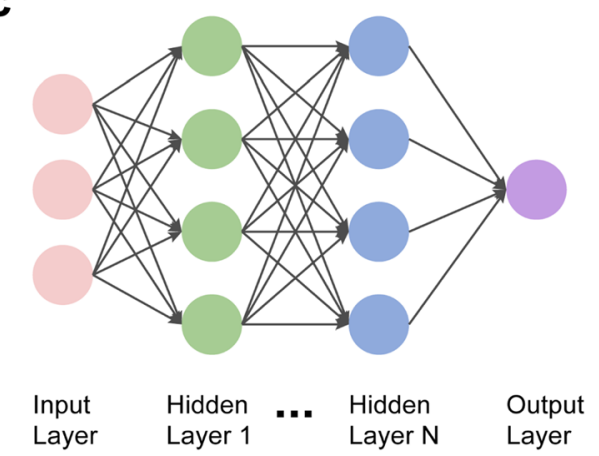

b
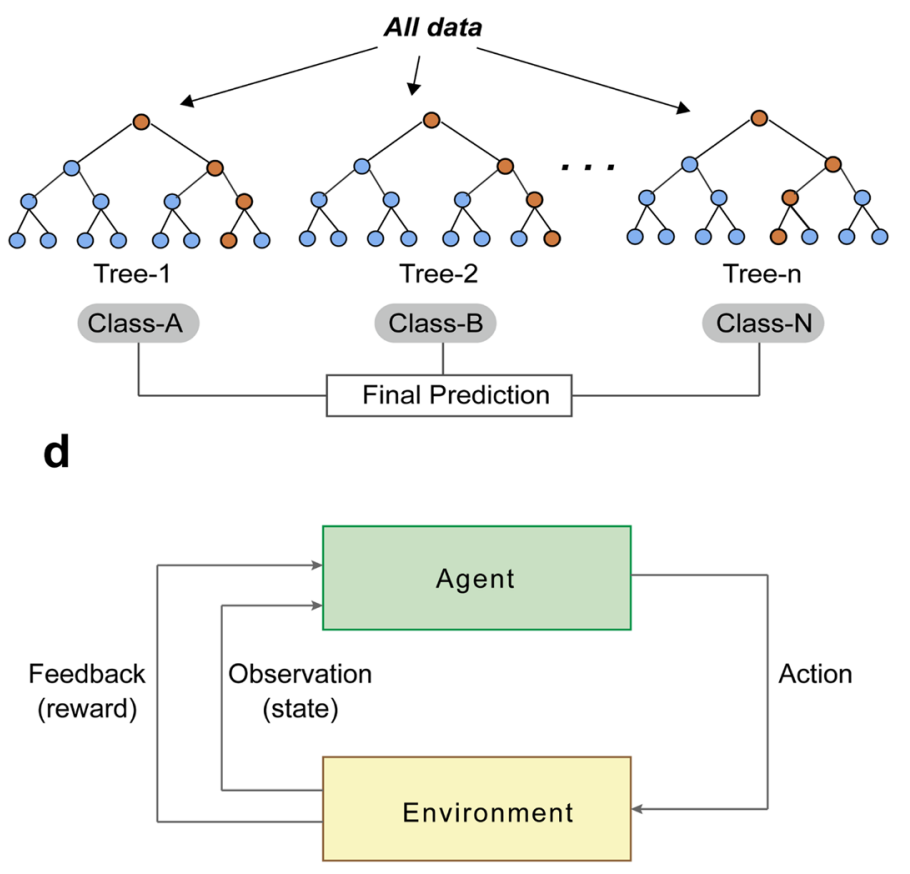

Fig. 3 Schematic diagram of common algorithms in Al. a SVM are supervised learning models used to analyze the classification and regression of data. $\mathbf{b}$ RFs are an ensemble learning method that use multiple trees to train and predict samples. c CNNs are composed of layers of stacked neurons that can learn complex functions. $\mathbf{d}$ Reinforcement learning algorithms are used to train the action of an agent on an environment. Abbreviations: SVM, support vector machine; RF, random forest; CNN, convolutional neural networks 


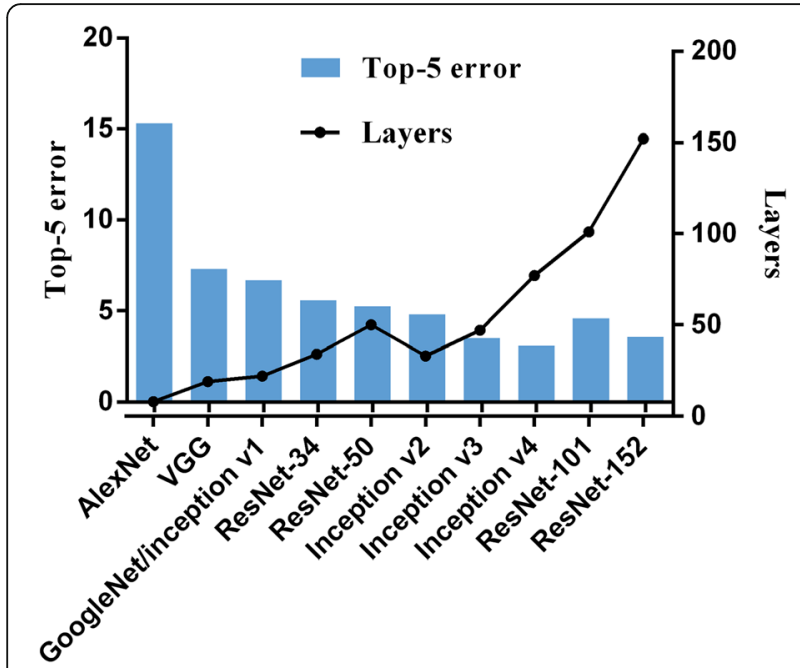

Fig. 4 Top-5 error of representative CNN algorithms. Top-5 error: The probability of which none of the first five most probable labels given by the image classification algorithm is correct. Abbreviations: VGG, visual geometry group; GoogleNet, google inception net; ResNet, residual network

GoogleNet [35] (Fig. 4), which showed robust performance in the ImageNet Large Scale Visual Recognition Competition [36] and has been successfully applied in facial detection [37], real-time language translation, robot navigation and pedestrian detection [38]. There are various open source tools for development and implementation of AI algorithms; these tools are compatible with many modern programming languages. We summarized some of the most commonly used libraries for DL in Fig. 5.

\section{Al models building progress}

DL neural networks use convolutional parameter layers to learn filters iteratively, which extract hierarchical feature maps from input images, learning the intricate structures of complicated features (such as shapes) through simpler features (such as line) and give the desired classification as output. These convolutional layers are placed in turn, so that each layer transforms the input image and propagates the output information into the next layer.

During the training progress, the parameters (mathematical functions) of the neural network are initially set to random values. The loss function is used to estimate the degree of inconsistency between the predicted value and the true value of the model. Next, the output provided by the function is compared to known features in the training set. Then, parameters of the function are slightly modified by the optimizer so that they can approximate or reach the optimal value, thereby minimizing the loss function. In general, the smaller the loss function, the better the model's robustness. This process is repeated many times, and the function "learns" how to accurately calculate the features from the pixel intensity of the image for all images in the training set. The most commonly used network is the $\mathrm{CNN}$, which uses a function that first merges nearby pixels into local features and then aggregates them into global features.

Figure $6 \mathrm{a}$ represents an abstraction of the algorithmic pipeline. The model characterizes the diagnosis of a disease based on an expert-labelled ground truth. The steps for building an AI model include pre-processing image data, training data, validating and testing the model from a large-scale dataset, and eventually evaluate the performance of the trained model.

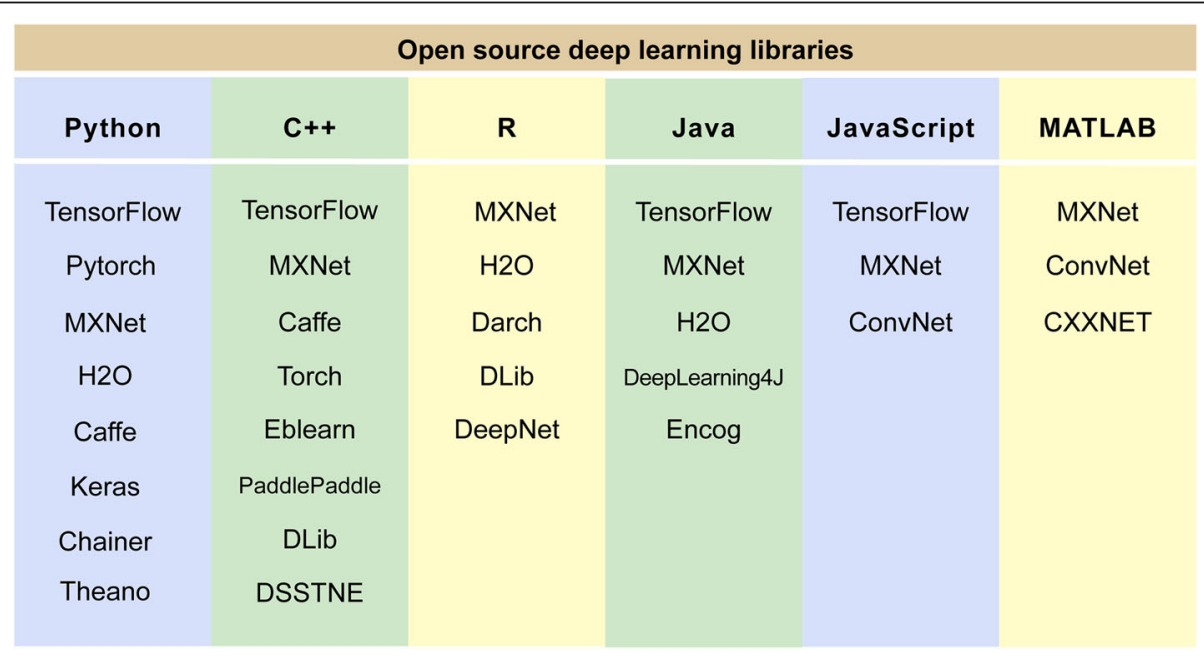

Fig. 5 Open source DL research libraries with major programming languages including Python, $C++, R$, Java. Python libraries tend to be the most popular and can be used to implement recently available algorithms. Abbreviations: DL, deep learning 

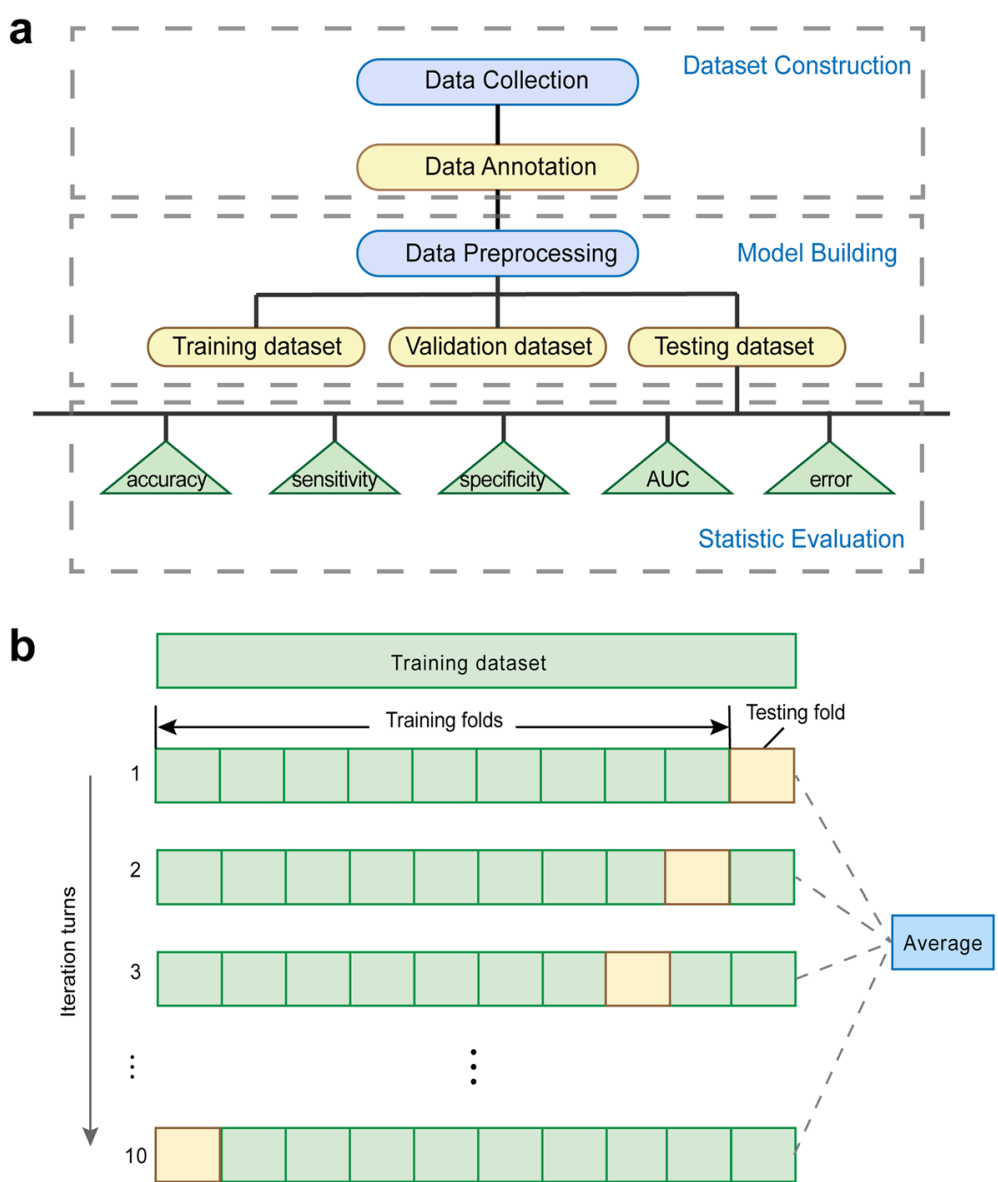

Fig. 6 A diagram showing data processing. a The typical workflow of Al experimental process. b Illustration of k-fold cross-validation techniques $(k=10)$. Abbreviation: AUC, area under the curve

\section{Image data preprocessing}

To unify images from different sources and rearrange them into a uniform format, multiple preprocessing steps can be performed [39]: (1) Cleaning up the data: It is the process of reviewing and verifying data, which can remove duplicate information and correct existing errors. (2) Data normalization: The original data will be resized to a common scale which is suitable for comprehensive comparative evaluation. (3) Noise reduction: It will greatly affect the convergence speed of the data and even the accuracy of the trained model if there are a lot of noise in the image data.

\section{Training, validation and testing}

To achieve a better performance, the base dataset is randomly split into two subsets: one for the model building; and one for testing the model's performance. The former dataset is further partitioned into training dataset and validation dataset. The training dataset is used to develop the learning model, the validation dataset is used for parameter selection and tuning, and the test dataset was used to evaluate the model.
During the training process, one way to optimize the model and estimate the accuracy of the algorithm when there are insufficient training samples is by using the cross-validation method [40]. All data for modeling is randomly partitioned into $\mathrm{k}$ equal sized complementary subsamples. (k-1) folds are selected as the training set and one is selected as the validation set. This process is then repeated across $k$ iterations using a different set of training and testing examples (Fig. 6b).

\section{Evaluation metrics}

After building the best learning model, evaluation indicators including accuracy, sensitivity and specificity are compared (Table 2). Furthermore, the receiver operating characteristic curve (ROC), and the area under the ROC curve (AUC) indicators are indicative of vital objective evaluation in the task of classification. AUC can measure the accuracies of the positive and negative samples at the same time. The closer the ROC curve is located to upper-left hand corner, the higher the value of AUC, and the better the model's performance will be. 
Table 2 Common metrics in Al model evaluation

\begin{tabular}{ll}
\hline Evaluation metrics & Definitions \\
\hline Accuracy & $\begin{array}{l}\text { The proportion of both positives and negatives that are correctly identified; the higher the accuracy, the } \\
\text { better the classifier }\end{array}$ \\
Sensitivity/Recall & The proportion of positives that are correctly identified \\
Specificity & The proportion of negatives that are correctly identified \\
Precision & The proportion of positives that are correctly identified among all positive identified samples \\
Kappa value & To show the actual agreement between two sets of observations \\
Dice coefficient/F1 score & Harmonic average of the precision and recall, where an F1 score reaches its best value at 1 and worst at 0
\end{tabular}

\section{Applications of $A \mathrm{I}$ in ophthalmic imaging}

Recently, there has been a considerable increase in the use of AI techniques for medical imaging, from processing to interpretation. MRI and CT are collectively used in more than $50 \%$ of current articles involving applications of AI in radiology, electroencephalography, electrocardiography, X-ray imaging, ultrasound imaging and angiography (Fig. 7a). Among the applications of AI in ophthalmology, research efforts have focused on diseases with high incidences, such as diabetic retinopathy (DR), glaucoma, age-related macular degeneration (AMD) and cataract (Fig. 7b).

AI may be useful for alleviating clinical workloads as it allows physicians with minimal experience to screen for diseases and detect them in an efficient and objective manner. In the field of ophthalmology, AI has gained increasing interest because it can be used in detecting clinically significant features for diagnostic and prognostic purposes. There have been a number of researches comparing performance between experts and algorithms in diagnosing different ophthalmic imaging modalities.

\section{Fundus photograph (FP)}

FP is a common ophthalmic imaging technique, in which optical cameras are used to obtain enlarged images of retinal tissues; these retinal photographs are suitable for monitoring, diagnosis, and treatment planning with respect to eye diseases. Various studies have involved the application of AI technology with FP to the diagnosis, grading and monitoring of eye diseases [41, 42].

All diabetic patients need regular retinal screening for early detection and timely treatment of DR [43, 44], which is a leading cause of preventable blindness that affects millions of people worldwide [45]. Specific hallmarks in early DR including exudates [46-48], cottonwool spots [49, 50], macular edema [51] and microaneurysms $[52,53]$ in the retina can be viewed by FP and identified by AI methods. Most model outputs

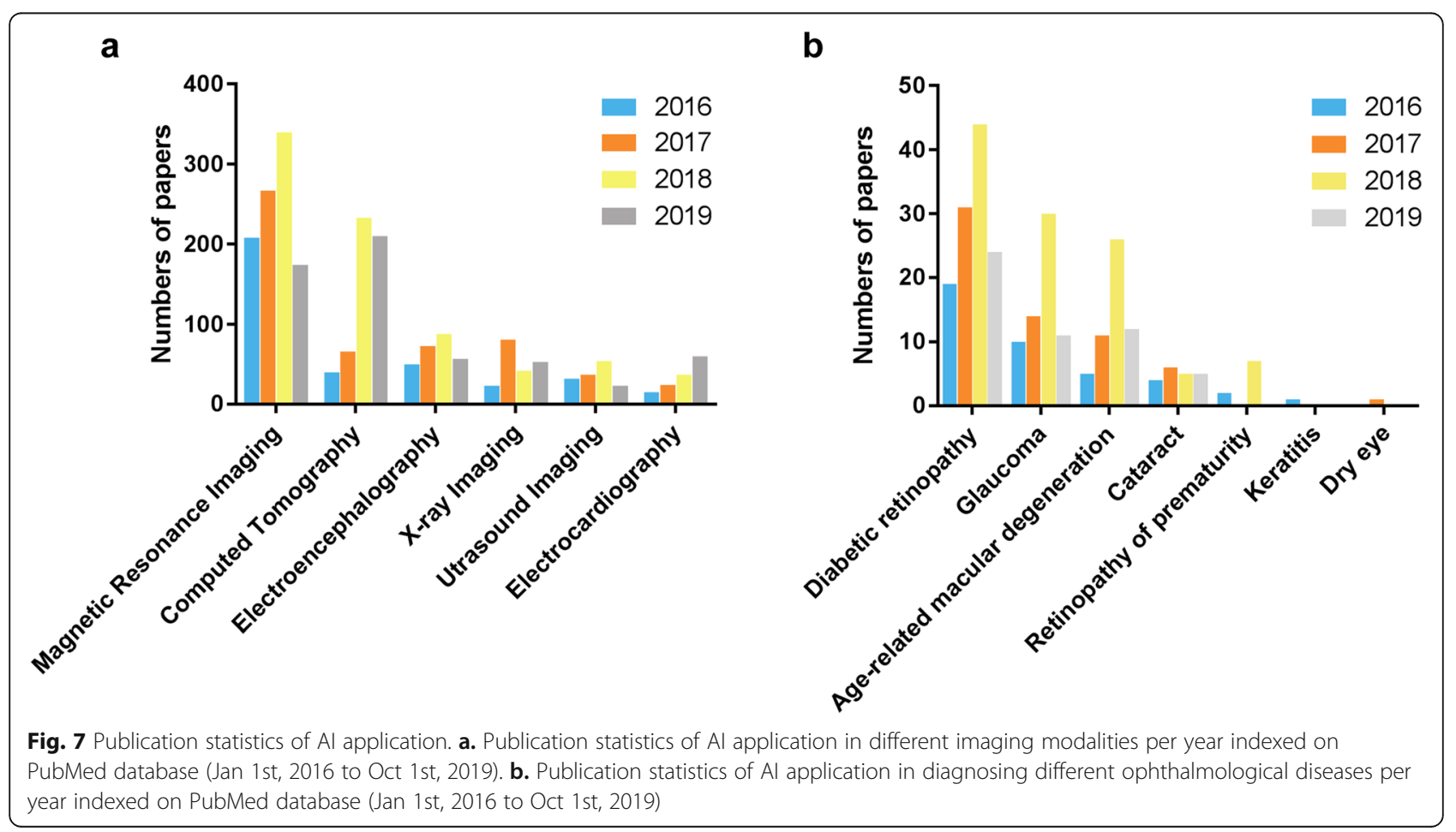


belong to binary or multi-class classification tasks. Gulshan et al. were the first to use a deep CNN (DCNN) for automated detection of DR [54]. In another study, with a large-scale dataset (494,661 retinal images), a DL system was developed to automatically detect DR, glaucoma, and AMD with respective AUCs of 93.6, 94.2 and 93.1\% [55]. Keel and colleagues developed a DL-based DR screening model for use in an endocrinology outpatient clinic, which resulted in 96\% patient satisfaction [56].

Generally, conventional FP involves the acquisition of photographs at one-field $45^{\circ}$ to the posterior pole of the retina, although the entire retina can be observed at an angle of $230^{\circ}$ [57]. Takahashi et al. constructed fundus images of four different shooting directions and trained the GoogleNet DCNN to study single fundus images or four synthetic fundus photos intelligently [58]. The results showed that the accuracy was higher for synthetic fundus images and suggested that wider ranges of fundus images should be used for DR diagnosis. Recently, ultra-wide field scanning laser ophthalmoscopy was introduced; this technology enables scanning of $80 \%$ of the fundus area [59]. Diagnosis with wide range FP is an emerging trend in AI diagnostic research, and more advanced algorithms are needed to support its continued growth.

AI can be used in clinical practice to analyze retinal images for disease screening. The Google Chips and Amazon DeepLens cameras, allow embedding of advanced algorithms within devices, which is a useful approach in various medical fields [60]. Rajalakshmi et al. combined an AI-based grading algorithm with a smartphone-based retinal imaging device for potential use in mass retinal screening of people with type 2 diabetes [61]. In 2018, IDx-DR was approved as the first fully autonomous AI-based DR diagnostic system by the United States Food and Drug Administration (FDA)
[62]; this study is a milestone as the first prospective assessment of AI in the real-world. We summarized the medical AI products approved by the FDA (Table 3).

In addition, FP can be used to diagnose other retinal diseases, such as glaucoma, retinopathy of prematurity (ROP), and AMD [63-67]. Recent efforts have aimed to automate pupillary tracking by integrating a motor into the fundus camera. Google Brain has been shown to predict subjects' cardiovascular risk factors, including age, systolic blood pressure, hemoglobin A1c, and sex from a single fundus image; this task is impossible for professional clinicians [68].

Important issues in the global implementation of ML/ DL are the use of big data sharing and open access to scientific data. We have summarized the most commonly used public data-sets of fundus photographs for model training (Table 4). Among them, Kaggle is one of the largest data modeling and data analysis competition platforms in the world, which provides over 50,000 retinal images taken under various shooting conditions, with $0-4$ severity level annotated by clinicians. Besides, EyePACS and MESSIDOR are the most commonly used image datasets for DR classification. At present, public eye datasets are mainly applied to automated DR and glaucoma detection, but few for other ophthalmic diseases.

\section{Optical coherence tomography (OCT)}

OCT is a non-contact and non-invasive optical imagebased diagnostic technology, which provides extensive information regarding retinal morphology and assists in the diagnosis of various macular diseases [76]. Thirty million ophthalmic OCT procedures are performed each year; this number is comparable in scale to other medical imaging modalities, such as MRI or CT [77-80].

Table 3 FDA cleared medical Al products

\begin{tabular}{|c|c|c|}
\hline Al products & Production companies & Applications \\
\hline Kardia App & Kardia Band, Alive Cor, United States & Clinical grade wearable electrocardiogram in Apple Watch \\
\hline The WAVE Clinical Platform & Excel Medical Electronics, United States & Patient surveillance and predictive algorithm platform \\
\hline Embrace Watch & Embrace, United States & The smartwatch that uses sensors to measure stress and predict seizures \\
\hline Viz LVO & Viz.Al, United States & Automatic detection of large vessel occlusion in suspected stroke patients \\
\hline Cognoa App & Cognoa, United States & An app based on ML that can help clinicians diagnose autism rapidly \\
\hline Guardian Connect & Medtronic, United States & $\begin{array}{l}\text { The continuous glucose monitoring system for people on multiple daily } \\
\text { insulin injections }\end{array}$ \\
\hline IDx-DR & IDx, United States & To automatic diagnose DR before it causes blindness \\
\hline OsteoDetect & Imagen Technologies, United States & $\begin{array}{l}\text { A type of computer-aided detection and diagnosis software designed to } \\
\text { detect wrist fractures in patients }\end{array}$ \\
\hline DreaMed Advisor Pro & DreaMed Diabetes, Petah Tikvah, Israel & Automated insulin pump setting adjustments in patients with type 1 diabetes \\
\hline Viz CTP & Viz.Al, United States & $\begin{array}{l}\text { A software package to perform image processing and analysis of CT perfusion } \\
\text { scans of the brain }\end{array}$ \\
\hline
\end{tabular}


Table 4 Common publicly available databases

\begin{tabular}{|c|c|c|c|c|}
\hline Datasets & Imaging Modalities & Population & Amount & Annotation \\
\hline Kaggle & FP & United States & 53,576 & DR \\
\hline EyePACS [54] & FP & United States & 35,126 & DR \\
\hline MESSIDOR [54] & FP & France & 1200 & DR; Macular edema \\
\hline E-OPHTHA [69] & FP & France & 463 & DR \\
\hline HRF [70] & FP & Germany & 45 & DR; Glaucoma; Optic Disk; Vessel; \\
\hline DRIVE & FP & Netherlands & 40 & DR; Vessel \\
\hline RIGA [71] & FP & France; Saudi Arabia & 760 & Glaucoma \\
\hline ORIGA-650 [72] & FP & Singapore & 650 & Glaucoma \\
\hline DRISHTI-GS [73] & FP & India & 101 & Glaucoma \\
\hline INSPRIRE-AVR [74] & FP & United States & 40 & Glaucoma \\
\hline REVIEW [75] & FP & United Kingdom & 16 & Vascular disease \\
\hline
\end{tabular}

$F P=$ fundus photograph; $D R=$ diabetic retinopathy

OCT algorithms can be broadly divided into classification and segmentation tasks.

With appropriate segmentation, the DL algorithm can extract and delineate the structures or lesions in OCT scans, then provide the surface areas or volumes of abnormal regions. Lee et al. applied a CNN model for segmentation of intraretinal fluid in OCT scans, which showed robust performance for interrater reliability between human observers and the algorithm [81]. Another group of patients was assessed regarding the need for urgent referral, using segmentation and classification algorithms. The system could transfer three-dimensional OCT scans into a tissue map and the patients were able to view the video showing the lesion, which sets a new benchmark for future efforts to solve the 'black box' problem of neural networks. Notably, the algorithm detected all urgent referral cases within the patient cohort [82]. With the development of DL, some researchers have extended their algorithms to perform segmentation of pigment epithelium detachment, fluid and vessels [83-85].

OCT has become increasingly important in disease detection, prognostication, and surveillance in AMD patients, especially those with wet AMD requiring antivascular endothelial growth factor (anti-VEGF). A ML method was proposed to predict the need for anti-VEGF treatment based on OCT scans taken during the intake examination. The results showed that classifications of low- and high-treatment requirement subgroups demonstrated AUCs of 0.7 and 0.77, respectively [86]. Treder et al. showed that a DL algorithm exhibited good performance for automated detection of AMD in spectral domain OCT [87]. This pilot study was an important step toward automated image-guided prediction of treatment intervals in patients with neovascular AMD.

Additionally, OCT can quantitatively measure structural parameters by scanning the thickness of the retinal nerve fiber layer (RNFL), which is recognized as the earliest structure being implicated in glaucoma [88], since the changes are often detectable before visual field loss [89]. ML classifiers have shown substantial diagnostic accuracy for detection of RNFL thickness measurements obtained by OCT [90, 91]. Moreover, algorithms have been developed for the use of OCT parameters to classify the optic disc in patients with open-angle glaucoma [92].

Because DL methods incorporate millions of parameters, the success of these methods largely depends on the availability of large datasets [93]. A DL-based computer-aided system was used to detect DR in a small sample of patients (52 OCT scans), achieving an AUC of 0.98 [94]. Transfer learning is an algorithm that enables the application of cumulative knowledge learned from other datasets to a new task [95]; this algorithm is highly effective with respect to the application of DL, particularly in the context of limited data [63]. An AI diagnostic tool based on a transfer learning algorithm could distinguish OCT images with choroidal neovascularization or diabetic macular edema from those of normal retina with an AUC of 98.9\% [96].

Recent research involved analysis of a unique combination of retinal OCT and MRI images; the findings indicated that retinal OCT might provide insights for early diagnosis of neurodegeneration in the brain, including Alzheimer's disease [97]. Taken together, the results of the above studies highlight the accuracy of diagnostic evaluation using AI.

\section{Slit-lamp images}

The slit lamp, a high-intensity light source instrument, is used to shine a thin beam of light into the eye, enabling examination of the anterior and posterior segments of the eye. It is applied mainly for wide illumination of much of the eye and its adnexa for general observation. 
In recent years, several studies have investigated and made contributions to the grading and classification of senile cataracts by using slit-lamp images. Huang et al. [98] proposed a ranking method based on slit-lamp images and achieved acceptable grading for nuclear cataracts; this could potentially reduce the clinical burden of experienced ophthalmologists. Fan et al. [99] developed an automatic grading system for nuclear sclerosis based on slit-lamp photographs, using linear regression; the grades predicted by that algorithm were statistically reliable. $\mathrm{Li}$ et al. [100] extracted important feature landmarks from slit-lamp images and trained an SVM regression model to automatically predict grades of nuclear cataract.

Slit-lamp images are essential in the diagnosis of congenital cataracts, a major cause of childhood blindness [101-103]. Compared with senile cataract, the phenotype of congenital cataract is far more complicated. Slitlamp images show heterogeneity among cataract patients as well as complexity in their ocular images [104, 105].

In addition, some DL methods for grading and classifying slit-lamp images have shown effective results [106, 107]. Lin and colleagues' team developed a prototype diagnostic and therapeutic system (CC-Cruiser) for pediatric cataract screening by using preprocessed ocular images and a DCNN [108]; they compared the performances of multiple DL and conventional ML methods from various perspectives $[109,110]$. CC-Cruiser has been used in the Ophthalmic Center of Sun Yat-sen University with an accuracy comparable to that of ophthalmologists. Lin and colleagues also built a collaborative cloud-based multihospital AI platform to integrate rare disease data and provide medical suggestions for non-specialized doctors and remote hospitals without advanced equipment. These efforts addressed significant needs in cataract research and may provide a basis for using AI to analyze other ophthalmic images.

With the continual increase in the amount of data available for AI analysis as well as the potential for AI to identify diseases, ophthalmic medical imaging has moved from a strictly conceptual and perceptual approach to more objective methodology. The enhanced efficiency provided by AI is likely to allow ophthalmologists to perform more value-added tasks. In this review, we summarized studies on FP and OCT using DL techniques on diseases with high incidences (Table 5).

\section{Challenges and future considerations}

Despite promising findings thus far, there remain challenges and limitations to using AI [138]. First, the quality of input images is inherently variable, primarily because there is a lack of uniform imaging annotation, and there is variability in ocular characteristics among patients. In addition, inter-expert variability in clinical decision making is an important issue which has been well-documented [139]. High inconsistency among experts in the interpretation of ophthalmic images may introduce bias during model training. Secondly, due to the heavy workload of manual annotation, the number of images with clinical annotations is extremely scarce. Hence, advanced image annotation tools should be developed to gather clinical annotations (such as localization of exudates and retinal hemorrhages). Semi-supervised learning method attempts to make full use of unlabeled samples to improve the performance of model generalization. Third, given the complexity of diseases, sufficient data are needed to build high-accuracy models; however, data for more severe stages of disease, as well as for rare diseases, are often insufficient. Fourth, the current application of AI in ophthalmology mainly focuses on single images of a single disease, whereas combined diagnosis using multiple imaging techniques is needed to evaluate diseases in a synergistic manner. Finally, ensuring the security and privacy of medical data is an important challenge that has not been entirely resolved.

In the future, healthcare systems with minimal staff may benefit from modern automated imaging. The inclusion of intelligence within ophthalmic devices may enable healthcare professionals to provide better patient care. Furthermore, AI systems may be embedded within ophthalmic imaging devices for real-time image diagnosis (e.g., portable fundus cameras and smartphones) with minimal operator expertise. Emerging multimodal imaging techniques, which coincide with improved intelligent algorithms, enable joint training from complementary modalities that have different strengths. This embedded AI will be enabled by improved hardware performance with decreasing cost. With the increasing employment of AI in medical care, patients could be self-screened without supervision before an ophthalmologist appointment. Besides, patients in remote areas could receive routine eye examinations and undergo monitoring of disease progression without the intervention of highly skilled operators. Increasing the interpretability of networks will be another important research direction. The "black box" problem has been identified as an obstacle to the application of DL in healthcare. Existing studies have developed novel algorithms that enable clinicians to inspect and visualize the decision process (e.g., OCT tissue-segmentation), rather than simply obtaining a diagnosis suggestion [82]. In terms of treatment, the research on ophthalmic robots needs further exploration; there have been studies on robotic intraretinal vascular injection and anterior macular surgery.

\section{Conclusions}

With the unprecedented progress of computer and imaging technologies, medical imaging has developed from an auxiliary examination to the most important method 
Table 5 Summary of DL methods using FP and OCT to detect eye disease

\begin{tabular}{|c|c|c|c|c|c|c|}
\hline Authors & Year & $\begin{array}{l}\text { Imaging } \\
\text { Modalities }\end{array}$ & Aim & Data sets & DL techniques & Performance \\
\hline $\begin{array}{l}\text { Arcadu F } \\
\text { et al. [111] }\end{array}$ & 2019 & FP & $\begin{array}{l}\text { Diabetic macular thickening } \\
\text { detection }\end{array}$ & $\begin{array}{l}\text { Local: } \\
17,997 \text { FPs }\end{array}$ & Inception-v3 & $\begin{array}{l}\text { AUC: } \\
0.97 \text { (central subfield thickness } \geq 250 \mu \mathrm{m} \text { ) } \\
0.91 \text { (central foveal thickness } \geq 250 \mu \mathrm{m} \text { ) } \\
0.94 \text { (central subfield thickness } \geq 400 \mu \mathrm{m} \text { ) } \\
0.96 \text { (central foveal thickness } \geq 400 \mu \mathrm{m} \text { ) }\end{array}$ \\
\hline $\begin{array}{l}\text { Nagasawa T } \\
\text { et al. [112] }\end{array}$ & 2019 & FP & $\begin{array}{l}\text { Treatment-naiive proliferative } \\
\text { diabetic retinopathy detection }\end{array}$ & $\begin{array}{l}\text { Local: } \\
132 \mathrm{FPs}\end{array}$ & VGG-16 & $\begin{array}{l}\text { Sensitivity: } 94.7 \% \\
\text { Specificity: } 97.2 \% \\
\text { AUC: } 0.969\end{array}$ \\
\hline $\begin{array}{l}\text { Phan S } \\
\text { et al. [113] }\end{array}$ & 2019 & FP & Glaucoma detection & $\begin{array}{l}\text { Local: } \\
3312 \text { FPs }\end{array}$ & $\begin{array}{l}\text { VGG-19 } \\
\text { ResNet-152 } \\
\text { DenseNet-201 }\end{array}$ & AUCs of 0.9 or more (3 DCNNs) \\
\hline $\begin{array}{l}\text { Nagasato D } \\
\text { et al. [114] }\end{array}$ & 2019 & FP & $\begin{array}{l}\text { Branch retinal vein occlusion } \\
\text { detection }\end{array}$ & $\begin{array}{l}\text { Local: } \\
466 \mathrm{FPs}\end{array}$ & $\begin{array}{l}\text { VGG-16 } \\
\text { SVM }\end{array}$ & $\begin{array}{l}\text { Sensitivity: } 94.0 \% \\
\text { Specificity: } 97.0 \% \\
\text { positive predictive value (PPV): } 96.5 \% \\
\text { negative predictive value (NPV): } 93.2 \% \\
\text { AUC: } 97.6 \%\end{array}$ \\
\hline $\begin{array}{l}\text { Burlina PM } \\
\text { et al. [115] }\end{array}$ & 2019 & FP & $\begin{array}{l}\text { To develop DL techniques for } \\
\text { synthesizing high-resolution } \\
\text { realistic fundus images }\end{array}$ & $\begin{array}{l}\text { Local: } \\
\text { 133,821 FPs }\end{array}$ & GAN & $\begin{array}{l}\text { AUC: } \\
0.9706 \text { (model trained on real data) } \\
0.9235 \text { (model trained on synthetic data) }\end{array}$ \\
\hline $\begin{array}{l}\text { Girard F } \\
\text { et al. [116] }\end{array}$ & 2019 & FP & $\begin{array}{l}\text { Joint segmentation and } \\
\text { classification of retinal arteries } \\
\text { and veins }\end{array}$ & $\begin{array}{l}\text { Public: } \\
\text { DRIVE, } 40 \text { FPs } \\
\text { MESSIDOR, } 1200 \text { FPs }\end{array}$ & CNN & $\begin{array}{l}\text { Accuracy: } 94.8 \% \\
\text { Sensitivity: } 93.7 \% \\
\text { Specificity: } 92.9 \%\end{array}$ \\
\hline $\begin{array}{l}\text { Coyner AS } \\
\text { et al. [117] }\end{array}$ & 2018 & FP & $\begin{array}{l}\text { Image quality assessment } \\
\text { of fundus images in ROP }\end{array}$ & $\begin{array}{l}\text { Local: } \\
6043 \text { FPs }\end{array}$ & VGG-19 DCNN & $\begin{array}{l}\text { Accuracy: } 89.1 \% \\
\text { AUC: } 0.964\end{array}$ \\
\hline $\begin{array}{l}\text { Keel S } \\
\text { et al. [118] }\end{array}$ & 2018 & FP & $\begin{array}{l}\text { Detection of referable } \\
\text { diabetic retinopathy and } \\
\text { glaucoma }\end{array}$ & $\begin{array}{l}\text { Public: } \\
\text { LabelMe, 114,906 FPs } \\
\text { (referable DR) }\end{array}$ & & $\begin{array}{l}\text { Sensitivity: } \\
\text { 90\% (glaucomatous optic neuropathy) } \\
96 \% \text { (referable DR) }\end{array}$ \\
\hline $\begin{array}{l}\text { Sayres R } \\
\text { et al. [119] }\end{array}$ & 2018 & FP & Assist grading for DR & $\begin{array}{l}\text { Public: } \\
\text { EyePACS, } 1796 \text { FPs }\end{array}$ & Inception v-4 & $\begin{array}{l}\text { Sensitivity: } \\
79.4 \% \text { (unassisted) } \\
87.5 \% \text { (grades only) } \\
88.7 \% \text { (grades plus heatmap) }\end{array}$ \\
\hline $\begin{array}{l}\text { Peng Y } \\
\text { et al. [120] }\end{array}$ & 2018 & FP & $\begin{array}{l}\text { Automated classification } \\
\text { of AMD severity }\end{array}$ & $\begin{array}{l}\text { Public: } \\
\text { AREDS, } 59302 \text { FPs }\end{array}$ & $\begin{array}{l}\text { DeepSeeNet } \\
\text { (Inception v-3) }\end{array}$ & $\begin{array}{l}\text { Accuracy: } 0.671 \\
\text { AUC: } \\
0.94 \text { (large drusen) } \\
0.93 \text { (pigmentary abnormalities) } \\
0.97 \text { (late AMD) }\end{array}$ \\
\hline $\begin{array}{l}\text { Guo Y } \\
\text { et al. [121] }\end{array}$ & 2018 & FP & Retinal vessel detection & $\begin{array}{l}\text { Public: } \\
\text { DRIVE, } 20 \mathrm{FPs} \\
\text { STARE, } 20 \mathrm{FPs}\end{array}$ & Multiple DCNNs & $\begin{array}{l}\text { Accuracy: } \\
\text { 95.97\% (DRIVE training dataset) } \\
\text { 96.13\% (DRIVE testing dataset) } \\
\text { 95.39\% (STARE dataset) } \\
\text { AUC: } \\
\text { 0,9726 (DRIVE training dataset) } \\
\text { 0.9737 (DRIVE testing dataset) } \\
\text { 0.9539 (STARE dataset) }\end{array}$ \\
\hline $\begin{array}{l}\text { Khojasteh P } \\
\text { et al. [122] }\end{array}$ & 2018 & FP & $\begin{array}{l}\text { Detection of exudates, } \\
\text { microaneurysms and } \\
\text { hemorrhages }\end{array}$ & $\begin{array}{l}\text { Public: } \\
\text { DIARETDB1, } 75 \text { FPs } \\
\text { e-Ophtha, } 209 \text { FPs }\end{array}$ & CNN & $\begin{array}{l}\text { Accuracy: } \\
\text { 97.3\% (DIARETDB1 dataset) } \\
86.6 \% \text { (e-Ophtha) } \\
\text { Sensitivity: } \\
0.96 \text { (exudates) } \\
0.84 \text { (hemorrhages) } \\
0.85 \text { (microaneurysms) }\end{array}$ \\
\hline $\begin{array}{l}\text { Gargeya R } \\
\text { et al. [123] }\end{array}$ & 2017 & FP & Automated identification of DR & $\begin{array}{l}\text { Public: } \\
\text { EyePACS, } 75,137 \\
\text { FPs MESSIDOR 2, } 1748 \\
\text { E-Ophtha, } 463 \text { FPs }\end{array}$ & DCNN & $\begin{array}{l}\text { Sensitivity: } 94 \% \\
\text { Specificity: } 98 \% \\
\text { AUC: } 0.97\end{array}$ \\
\hline $\begin{array}{l}\text { Burlina PM } \\
\text { et al. [63] }\end{array}$ & 2017 & FP & Automated grading of AMD & $\begin{array}{l}\text { Public: } \\
\text { AREDS, more than } 130,000 \mathrm{FPs}\end{array}$ & DCNN & $\begin{array}{l}\text { Accuracy: } \\
88.4 \%(\text { SD, } 0.5 \%)-91.6 \% \\
\text { (SD, } 0.1 \%) \\
\text { AUC: } 0.94 \text { (SD, } 0.5 \%)-0.96 \\
\text { (SD, } 0.1 \%)\end{array}$ \\
\hline $\begin{array}{l}\text { Ordóñez PF } \\
\text { et al. [124] }\end{array}$ & 2017 & FP & $\begin{array}{l}\text { To improve the accuracy of } \\
\text { microaneurysms detection }\end{array}$ & $\begin{array}{l}\text { Public: } \\
\text { Kaggle, } 88,702 \text { FPs } \\
\text { Messidor, } 1200 \mathrm{FPs} \\
\text { DiaRerDB1, } 89 \mathrm{FPs}\end{array}$ & $\begin{array}{l}\text { Standard CNN } \\
\text { VGG CNN }\end{array}$ & $\begin{array}{l}\text { Sensitivity }>91 \% \\
\text { Specificity }>93 \% \\
\text { AUC }>93 \%\end{array}$ \\
\hline
\end{tabular}


Table 5 Summary of DL methods using FP and OCT to detect eye disease (Continued)

\begin{tabular}{|c|c|c|c|c|c|c|}
\hline Authors & Year & $\begin{array}{l}\text { Imaging } \\
\text { Modalities }\end{array}$ & Aim & Data sets & $\mathrm{DL}$ techniques & Performance \\
\hline $\begin{array}{l}\text { Takahashi H } \\
\text { et al. [58] }\end{array}$ & 2017 & $\mathrm{FP}$ & Improving staging of DR & $\begin{array}{l}\text { Local: } \\
9939 \text { FPs }\end{array}$ & $\begin{array}{l}\text { GoogleNet } \\
\text { DCNN }\end{array}$ & $\begin{array}{l}\text { Prevalence and bias-adjusted } \\
\text { Fleiss'kappa (PABAK): } \\
0.64 \text { (modified Davis grading) } \\
0.37 \text { (real prognosis grading) }\end{array}$ \\
\hline $\begin{array}{l}\text { Abbas Q } \\
\text { et al. [125] }\end{array}$ & 2017 & FP & $\begin{array}{l}\text { Automatic recognition of } \\
\text { severity level of DR }\end{array}$ & $\begin{array}{l}\text { Local: } \\
750 \text { FPs }\end{array}$ & DCNN & $\begin{array}{l}\text { Sensitivity: } 92.18 \% \\
\text { Specificity: } 94.50 \% \\
\text { AUC: } 0.924\end{array}$ \\
\hline $\begin{array}{l}\text { Pfister M } \\
\text { et al. [126] }\end{array}$ & 2019 & OCT & $\begin{array}{l}\text { Automated segmentation of } \\
\text { dermal fillers in OCT images }\end{array}$ & $\begin{array}{l}\text { Local: } \\
100 \text { OCT volume data sets }\end{array}$ & $\begin{array}{l}\text { CNN } \\
\text { (U-net-like } \\
\text { architecture) }\end{array}$ & $\begin{array}{l}\text { Accuracy: } \\
0.9938\end{array}$ \\
\hline $\begin{array}{l}\text { Fu H } \\
\text { et al. [127] }\end{array}$ & 2019 & OCT & $\begin{array}{l}\text { Automated angle-closure } \\
\text { detection }\end{array}$ & $\begin{array}{l}\text { Local: } \\
4135 \text { anterior segment OCT images }\end{array}$ & CNN & $\begin{array}{l}\text { Sensitivity: } 0.79 \pm 0.037 \\
\text { Specificity: } 0.87 \pm 0.009 \\
\text { AUC: } 0.90\end{array}$ \\
\hline $\begin{array}{l}\text { Masood S } \\
\text { et al. [128] }\end{array}$ & 2019 & OCT & $\begin{array}{l}\text { Automatic choroid layer } \\
\text { segmentation from OCT } \\
\text { images }\end{array}$ & $\begin{array}{l}\text { Local: } \\
525 \text { OCT images }\end{array}$ & $\begin{array}{l}\text { CNN } \\
\text { (Cifar-10 model) }\end{array}$ & Accuracy: $97 \%$ \\
\hline $\begin{array}{l}\text { Dos Santos } \\
\text { VA et al. } \\
\text { [129] }\end{array}$ & 2019 & OCT & $\begin{array}{l}\text { Segmentation of cornea } \\
\text { OCT scans }\end{array}$ & $\begin{array}{l}\text { Local: } \\
\text { 20,160 OCT images }\end{array}$ & CNN & Accuracy: $99.56 \%$ \\
\hline $\begin{array}{l}\text { Asaoka R } \\
\text { et al. [130] }\end{array}$ & 2019 & OCT & $\begin{array}{l}\text { Diagnosis early-onset } \\
\text { glaucoma from OCT images }\end{array}$ & $\begin{array}{l}\text { Local: } \\
4316 \text { OCT images }\end{array}$ & CNN & AUC: $93.7 \%$ \\
\hline $\begin{array}{l}\text { Lu W } \\
\text { et al. [131] }\end{array}$ & 2018 & OCT & $\begin{array}{l}\text { Classification of multi-categorical } \\
\text { abnormalities from OCT images }\end{array}$ & $\begin{array}{l}\text { Local: } \\
60,407 \text { OCT images }\end{array}$ & ResNet & $\begin{array}{l}\text { Accuracy: } 0.959 \\
\text { AUC: } 0.984\end{array}$ \\
\hline $\begin{array}{l}\text { Schlegl T } \\
\text { et al. [132] }\end{array}$ & 2018 & OCT & $\begin{array}{l}\text { Detection of macular fluid in } \\
\text { OCT images }\end{array}$ & $\begin{array}{l}\text { Local: } \\
1200 \text { OCT scans }\end{array}$ & CNN & $\begin{array}{l}\text { Intraretinal cystoid fluid detection: } \\
\text { Accuracy: } 0.91 \\
\text { AUC: } 0.94 \\
\text { Subretinal fluid detection: } \\
\text { Accuracy: } 0.61 \\
\text { AUC: } 0.92\end{array}$ \\
\hline $\begin{array}{l}\text { Prahs P } \\
\text { et al. [133] }\end{array}$ & 2018 & OCT & $\begin{array}{l}\text { Evaluation of treatment } \\
\text { indication with anti-vascular } \\
\text { endothelial growth factor } \\
\text { medications }\end{array}$ & $\begin{array}{l}\text { Local: } \\
183,402 \text { OCT scans }\end{array}$ & $\begin{array}{l}\text { GoogleNet } \\
\text { inception } \\
\text { DCNN }\end{array}$ & $\begin{array}{l}\text { Accuracy: } 95.5 \% \\
\text { Sensitivity: } 90.1 \% \\
\text { Specificity: } 96.2 \% \\
\text { AUC: } 0.968\end{array}$ \\
\hline $\begin{array}{l}\text { Shah A } \\
\text { et al. [134] }\end{array}$ & 2018 & OCT & $\begin{array}{l}\text { Retinal layer segmentation in } \\
\text { OCT images }\end{array}$ & $\begin{array}{l}\text { Local: } \\
3000 \text { OCT scans }\end{array}$ & CNN & Average computation time: $12.3 \mathrm{~s}$ \\
\hline $\begin{array}{l}\text { Chan GCY } \\
\text { et al. [135] }\end{array}$ & 2018 & OCT & $\begin{array}{l}\text { Automated diabetic macular } \\
\text { edema classification }\end{array}$ & $\begin{array}{l}\text { Public: } \\
\text { Singapore Eye Research } \\
\text { Institute, 14,720 OCT scans }\end{array}$ & $\begin{array}{l}\text { AlexNet, VGG, } \\
\text { GoogleNet }\end{array}$ & Accuracy: 93.75\% \\
\hline $\begin{array}{l}\text { Muhammad } \\
\mathrm{H} \text { et al. [136] }\end{array}$ & 2017 & OCT & $\begin{array}{l}\text { Classification of glaucoma } \\
\text { suspects }\end{array}$ & Local:102 OCT scans & $\begin{array}{l}\text { CNN, Random } \\
\text { forest }\end{array}$ & $\begin{array}{l}\text { Accuracy: } 93.1 \% \text { (retinal } \\
\text { nerve fiber layer) }\end{array}$ \\
\hline $\begin{array}{l}\text { Lee CS } \\
\text { et al. [81] }\end{array}$ & 2017 & OCT & $\begin{array}{l}\text { Segmentation of macular } \\
\text { edema in OCT }\end{array}$ & Local:1289 OCT images & U-Net CNN & $\begin{array}{l}\text { cross-validated Dice } \\
\text { coefficient: } 0.911\end{array}$ \\
\hline $\begin{array}{l}\text { Lee CS } \\
\text { et al. [137] }\end{array}$ & 2017 & OCT & $\begin{array}{l}\text { Classification of normal and } \\
\text { AMD OCT images }\end{array}$ & $\begin{array}{l}\text { Public:Electronic medical records, } \\
\text { 101,002 OCT images }\end{array}$ & VGG-16 & $\begin{array}{l}\text { Accuracy: } 87.63 \% \\
\text { AUC: } 92.78 \%\end{array}$ \\
\hline
\end{tabular}

$D L=$ deep learning; $F P=$ fundus photography; $O C T=$ optical coherence tomography; $C N N=$ convolution neural network; $D C N N=$ deep convolution neural network; $D R=$ diabetic retinopathy; $A M D=$ age-related macular degeneration; $A U C=$ area under the curve

for clinical and differential diagnosis in modern medicine. High-accuracy models suggest that ML can effectively learn from increasingly complicated images with a high degree of generalization, using a relatively small repository of data [68]. To some extent, AI may revolutionize disease diagnosis and management by performing classifications of difficult images for clinical experts, as well as by rapidly reviewing large amounts of images. Compared with evaluations by humans, AI has advantages in terms of information integration, data processing, and diagnostic speed. Most AI-based applications in medicine are still in early stages; AI in medical care may ultimately aid in expediting the diagnosis and referral of ophthalmic diseases through crossdisciplinary collaborations of clinicians, engineers, and designers.

\section{Acknowledgements}

Not applicable.

\section{Authors' contributions}

Y.T. was involved in scientific literature research and writing the manuscript. Y.S. was involved in designing the protocol, and reviewing and editing the manuscript. W.L. and Y.Y. was involved in the 
conception and editing of the manuscript. All authors read and approved the final manuscript.

\section{Funding}

This work was supported by National Key R\&D Program of China (2017YFE0103400); National Nature Science Foundation of China (Grant No. 81800872)

\section{Availability of data and materials}

Not applicable.

\section{Ethics approval and consent to participate}

Not applicable.

\section{Competing interests}

The authors declare that they have no competing interests.

Received: 16 October 2019 Accepted: 10 March 2020

Published online: 16 April 2020

\section{References}

1. Bernardes R, Serranho P, Lobo C. Digital ocular fundus imaging: a review. Ophthalmologica. 2011;226(4):161-81.

2. Panwar N, Huang P, Lee J, Keane PA, Chuan TS, Richhariya A, et al. Fundus photography in the 21st century--a review of recent technological advances and their implications for worldwide healthcare. Telemed J E Health. 2016; 22(3):198-208

3. Zhang Z, Srivastava R, Liu H, Chen X, Duan L, Kee Wong DW, et al. A survey on computer aided diagnosis for ocular diseases. BMC Med Inform Decis Mak. 2014;14:80

4. Chaikitmongkol V, Khunsongkiet P, Patikulsila D, Ratanasukon M, Watanachai $\mathrm{N}$, Jumroendararasame $\mathrm{C}$, et al. Color fundus photography, optical coherence tomography, and fluorescein angiography in diagnosing polypoidal choroidal vasculopathy. Am J Ophthalmol. 2018;192:77-83.

5. Obermeyer Z, Lee TH. Lost in thought - the limits of the human mind and the future of medicine. N Engl J Med. 2017;377(13):1209-11.

6. Murdoch TB, Detsky AS. The inevitable application of big data to health care. JAMA. 2013;309(13):1351-2.

7. Patel VL, Shortliffe EH, Stefanelli M, Szolovits P, Berthold MR, Bellazzi R, et al. The coming of age of artificial intelligence in medicine. Artif Intell Med. 2009:46(1):5-17.

8. Esteva A, Kuprel B, Novoa RA, Ko J, Swetter SM, Blau HM, et al. Dermatologist-level classification of skin cancer with deep neural networks. Nature. 2017;542(7639):115-8.

9. van Ginneken B. Fifty years of computer analysis in chest imaging: rule-based machine learning, deep learning. Radiol Phys Technol. 2017:10(1):23-32.

10. Weng SF, Reps J, Kai J, Garibaldi JM, Qureshi N. Can machine-learning improve cardiovascular risk prediction using routine clinical data? PLoS One. 2017;12(4):e0174944

11. Schoepf UJ, Schneider AC, Das M, Wood SA, Cheema Jl, Costello P. Pulmonary embolism: computer-aided detection at multidetector row spiral computed tomography. J Thorac Imaging. 2007;22(4):319-23.

12. Bejnordi BE, Zuidhof $G$, Balkenhol M, Hermsen M, Bult $P$, van Ginneken B, et al. Context-aware stacked convolutional neural networks for classification of breast carcinomas in whole-slide histopathology images. J Med Imaging (Bellingham). 2017;4(4):044504.

13. Komeda $Y$, Handa $H$, Watanabe $T$, Nomura T, Kitahashi M, Sakurai T, et al. Computer-aided diagnosis based on convolutional neural network system for colorectal polyp classification: preliminary experience. Oncology. 2017; 93(Suppl 1):30-4.

14. Li Z, Wang Y, Yu J, Guo Y, Cao W. Deep Learning based Radiomics (DLR) and its usage in noninvasive IDH1 prediction for low grade glioma. Sci Rep. 2017;7(1):5467

15. Ambastha AK, Leong TY. Alzheimer's disease neuroimaging I. A deep learning approach to neuroanatomical characterisation of Alzheimer's disease. Stud Health Technol Inform. 2017;245:1249.

16. Mitchell TM, Shinkareva SV, Carlson A, Chang KM, Malave VL, Mason RA, et al. Predicting human brain activity associated with the meanings of nouns. Science. 2008;320(5880):1191-5.
17. Kim D, Burge J, Lane T, Pearlson GD, Kiehl KA, Calhoun VD. Hybrid ICABayesian network approach reveals distinct effective connectivity differences in schizophrenia. Neuroimage. 2008:42(4):1560-8.

18. Jiang $F$, Jiang $Y$, Zhi H, Dong $Y, L i ~ H, ~ M a ~ S$, et al. Artificial intelligence in healthcare: past, present and future. Stroke Vasc Neurol. 2017;2(4):230-43.

19. Russell S, Bohannon J. Artificial intelligence. Fears of an Al pioneer Science. 2015;349(6245):252.

20. Rokach L, Maimon O. Data mining with decision trees: theory and applications. World scientific: Singapore; 2008.

21. Lowd D, Domingos P. Naive Bayes models for probability estimation. In: Proceedings of the 22nd International Conference On Machine Learning (ICML 2005). Bonn: ACM; 2005. p. 529-36.

22. Cutler A, Cutler DR, Stevens JR. Random forests. In: Zhang C, Ma Y, editors Ensemble machine learning. Berlin: Springer; 2012. p. 157-75.

23. Ragab DA, Sharkas M, Marshall S, Ren J. Breast cancer detection using deep convolutional neural networks and support vector machines. Peer J. 2019;7:e6201.

24. Cortes C, Vapnik V. Support-vector networks. Mach Learn. 1995;20(3):273-97.

25. Cover T, Hart P. Nearest neighbor pattern classification. IEEE Trans Inf Theory. 1967;13(1):21-7.

26. LeCun Y, Bengio Y, Hinton G. Deep learning. Nature. 2015;521(7553): 436-44.

27. Hinton GE, Osindero S, Teh YW. A fast learning algorithm for deep belief nets. Neural Comput. 2006;18(7):1527-54.

28. Hinton GE, Salakhutdinov RR. Reducing the dimensionality of data with neural networks. Science. 2006;313(5786):504-7.

29. Lawrence S, Giles CL, Tsoi AC, Back AD. Face recognition: a convolutional neural-network approach. IEEE Trans Neural Netw. 1997;8(1):98-113.

30. Karpathy A, Fei-Fei L. Deep visual-semantic alignments for generating image descriptions. IEEE Trans Pattern Anal Mach Intell. 2017:39(4):664-76.

31. Choi E, Schuetz A, Stewart WF, Sun J. Using recurrent neural network models for early detection of heart failure onset. J Am Med Inform Assoc. 2017;24(2):361-70

32. Lecun Y, Bottou L, Bengio Y, Haffner P. Gradient-based learning applied to document recognition. Proc IEEE. 1998;86(11):2278-324.

33. Krizhevsky A, Sutskever I, Hinton GE. ImageNet classification with deep convolutional neural networks. Commun ACM. 2017;60(6):84-90.

34. He K, Zhang X, Ren S, Sun J. Deep residual learning for image recognition. In: 2016 IEEE Conference on Computer Vision and Pattern Recognition (CVPR). Las Vegas; 2016. p. 770-778.

35. Szegedy C, Wei L, Yangqing J, Sermanet P, Reed S, Anguelov D, et al. Going deeper with convolutions. In: 2015 IEEE conference on computer vision and pattern recognition (CVPR). Boston, MA; 2015. p. 1-9.

36. Russakovsky O, Deng J, Su H, Krause J, Satheesh S, Ma S, et al. ImageNet large scale visual recognition challenge. Int J Comput Vis. 2015;115(3):211-52

37. Fok Hing Chi T, Bouzerdown A. An eye feature detector based on convolutional neural network. In: Proceedings of the Eighth International Symposium on Signal Processing and its Applications, 2005. Sydney: IEEE; 2005. p. 90-93.

38. Szarvas M, Yoshizawa A, Yamamoto M, Ogata J. Pedestrian detection with convolutional neural networks. IEEE Proceedings. Intelligent Vehicles Symposium, 2005. Las Vegas; 2005. p. 224-229.

39. Xiaosong J, Yijun H. Research on data pre-process and feature extraction based on wavelet packet analysis. In: 2006 6th World Congress on Intelligent Control and Automation. Dalian; 2006. p. 5850-5853.

40. Cherkassky $\vee$. The nature of statistical learning theory. IEEE Trans Neural Netw. 1997;8(6):1564.

41. Guo Y, Budak Ü, Vespa LJ, Khorasani E, Şengür A. A retinal vessel detection approach using convolution neural network with reinforcement sample learning strategy. Measurement. 2018;125:586-91.

42. Guo Y, Budak Ü, Şengür A, Smarandache F. A retinal vessel detection approach based on shearlet transform and indeterminacy filtering on fundus images. Symmetry. 2017;9(10):235.

43. Fong DS, Aiello LP, Ferris FL 3rd, Klein R. Diabetic retinopathy. Diabetes Care. 2004:27(10):2540-53.

44. Namperumalsamy P, Nirmalan PK, Ramasamy K. Developing a screening program to detect sight-threatening diabetic retinopathy in South India. Diabetes Care. 2003;26(6):1831-5.

45. Cheung N, Mitchell P, Wong TY. Diabetic retinopathy. Lancet. 2010; 376(9735):124-36 
46. Osareh A, Shadgar B, Markham R. A computational-intelligence-based approach for detection of exudates in diabetic retinopathy images. IEEE Trans Inf Technol Biomed. 2009;13(4):535-45.

47. Shuang Y, Di X, Kanagasingam Y. Exudate detection for diabetic retinopathy with convolutional neural networks. Conf Proc IEEE Eng Med Biol Soc. 2017; 2017:1744-7.

48. Zheng R, Liu L, Zhang S, Zheng C, Bunyak F, Xu R, et al. Detection of exudates in fundus photographs with imbalanced learning using conditional generative adversarial network. Biomed Opt Express. 2018;9(10):4863-78.

49. Naqvi SAG, Zafar HMF, UI HI. Automated system for referral of cotton-wool spots. Curr Diabetes Rev. 2018;14(2):168-74.

50. Niemeijer M, van Ginneken B, Russell SR, Suttorp-Schulten MS, Abramoff MD. Automated detection and differentiation of drusen, exudates, and cotton-wool spots in digital color fundus photographs for diabetic retinopathy diagnosis. Invest Ophthalmol Vis Sci. 2007; 48(5):2260-7.

51. Murugeswari S, Sukanesh R. Investigations of severity level measurements for diabetic macular oedema using machine learning algorithms. Ir J Med Sci. 2017;186(4):929-38.

52. Jiayi W, Jingmin $X$, Lai H, You J, Nanning Z. New hierarchical approach for microaneurysms detection with matched filter and machine learning. Conf Proc IEEE Eng Med Biol Soc. 2015;2015:4322-5.

53. Budak U, Sengür A, Guo Y, Akbulut Y. A novel microaneurysms detection approach based on convolutional neural networks with reinforcement sample learning algorithm. Health Inf Sci Syst. 2017;5(1):14.

54. Gulshan V, Peng L, Coram M, Stumpe MC, Wu D, Narayanaswamy A, et al. Development and validation of a deep learning algorithm for detection of diabetic retinopathy in retinal fundus photographs. JAMA. 2016;316(22): 2402-10.

55. Ting DSW, Cheung CY, Lim G, Tan GSW, Quang ND, Gan A, et al. Development and validation of a deep learning system for diabetic retinopathy and related eye diseases using retinal images from multiethnic populations with diabetes. JAMA. 2017;318(22):2211-23.

56. Keel S, Lee PY, Scheetz J, Li Z, Kotowicz MA, Maclsaac RJ, et al. Feasibility and patient acceptability of a novel artificial intelligence-based screening model for diabetic retinopathy at endocrinology outpatient services: a pilot study. Sci Rep. 2018;8(1):4330.

57. Vujosevic S, Benetti E, Massignan F, Pilotto E, Varano M, Cavarzeran F, et al. Screening for diabetic retinopathy: 1 and 3 nonmydriatic 45-degree digital fundus photographs vs 7 standard early treatment diabetic retinopathy study fields. Am J Ophthalmol. 2009;148(1):111-8.

58. Takahashi H, Tampo H, Arai Y, Inoue Y, Kawashima H. Applying artificial intelligence to disease staging: deep learning for improved staging of diabetic retinopathy. PLoS One. 2017;12(6):e0179790.

59. Kaines A, Oliver S, Reddy S, Schwartz SD. Ultrawide angle angiography for the detection and management of diabetic retinopathy. Int Ophthalmol Clin. 2009;49(2):53-9.

60. Göbl R, Navab N, Hennersperger C. SUPRA: open-source software-defined ultrasound processing for real-time applications. Int J Comput Assist Radiol Surg. 2018;13(6):759-67.

61. Rajalakshmi R, Subashini R, Anjana RM, Mohan V. Automated diabetic retinopathy detection in smartphone-based fundus photography using artificial intelligence. Eye (Lond). 2018;32(6):1138-44.

62. Abràmoff MD, Lavin PT, Birch M, Shah N, Folk JC. Pivotal trial of an autonomous Al-based diagnostic system for detection of diabetic retinopathy in primary care offices. NPJ Digit Med. 2018;1:39.

63. Burlina PM, Joshi N, Pekala M, Pacheco KD, Freund DE, Bressler NM. Automated grading of age-related macular degeneration from color fundus images using deep convolutional neural networks. JAMA Ophthalmol. 2017; 135(11):1170-6

64. Xiangyu C, Yanwu X, Damon Wing Kee W, Tien Yin W, Jiang L. Glaucoma detection based on deep convolutional neural network. Conf Proc IEEE Eng Med Biol Soc. 2015;2015:715-8.

65. Li Z, He Y, Keel S, Meng W, Chang RT, He M. Efficacy of a deep learning system for detecting glaucomatous optic neuropathy based on color fundus photographs. Ophthalmology. 2018;125(8):1199-206.

66. Annan L, Jun C, Damon Wing Kee W, Jiang L. Integrating holistic and local deep features for glaucoma classification. Conf Proc IEEE Eng Med Biol Soc. 2016;2016:1328-31.

67. Burlina P, Pacheco KD, Joshi N, Freund DE, Bressler NM. Comparing humans and deep learning performance for grading AMD: a study in using universal deep features and transfer learning for automated AMD analysis. Comput Biol Med. 2017;82:80-6.

68. Poplin R, Varadarajan AV, Blumer K, Liu Y, McConnell MV, Corrado GS, et al. Prediction of cardiovascular risk factors from retinal fundus photographs via deep learning. Nat Biomed Eng. 2018;2(3):158-64.

69. Decencière E, Cazuguel G, Zhang X, Thibault G, Klein JC, Meyer F, et al. TeleOphta: machine learning and image processing methods for teleophthalmology. IRBM. 2013;34(2):196-203.

70. Budai A, Bock R, Maier A, Hornegger J, Michelson G. Robust Vessel Segmentation in Fundus Images. Int J Biomed Imaging. 2013;2013:154860.

71. Almazroa A, Alodhayb S, Osman E, Lakshminarayanan V, Raahemifar K, Alkatee M, Dlaim M, et al. Retinal fundus images for glaucoma analysis: the RIGA dataset. Med Imag 2018. 2018;2018:105790.

72. Zhuo Z, Feng Shou Y, Jiang L, Wing Kee W, Ngan Meng T, Beng Hai L, et al. ORIGA-light: An online retinal fundus image database for glaucoma analysis and research. In: 2010 Annual International Conference of the IEEE Engineering in Medicine and Biology. Buenos Aires; 2010. p. 3065-3068.

73. Sivaswamy J, Krishnadas SR, Datt Joshi G, Jain M, Syed Tabish AU, Drishti GS Retinal image dataset for optic nerve head(ONH) segmentation. In: 2014 IEEE 11th International Symposium on Biomedical Imaging (ISBI). Beijing; 2014. p. 53-56.

74. Niemeijer M, Xiayu X, Dumitrescu AV, Gupta P, van Ginneken B, Folk JC, et al. Automated measurement of the arteriolar-to-venular width ratio in digital color fundus photographs. IEEE Trans on Med Imaging. 2011;30(11): 1941-50.

75. Al-Diri B, Hunter A, Steel D, Habib M, Hudaib T, Berry S. Review - A reference data set for retinal vessel profiles. In: 2008 30th annual international conference of the IEEE engineering in medicine and biology society. Vancouver, BC; 2008. p. 2262-5.

76. Huang D, Swanson EA, Lin CP, Schuman JS, Stinson WG, Chang W, et al. Optical coherence tomography. Science. 1991;254(5035):1178-81.

77. Akhtar Z, Rishi P, Srikanth R, Rishi E, Bhende M, Raman R. Choroidal thickness in normal Indian subjects using swept source optical coherence tomography. PLoS One. 2018;13(5):e0197457.

78. Zysk AM, Nguyen FT, Oldenburg AL, Marks DL, Boppart SA. Optical coherence tomography: a review of clinical development from bench to bedside. J Biomed Opt. 2007;12(5):051403.

79. Adhi M, Duker JS. Optical coherence tomography--current and future applications. Curr Opin Ophthalmol. 2013;24(3):213-21.

80. Gabriele ML, Wollstein G, Ishikawa H, Kagemann L, Xu J, Folio LS, et al Optical coherence tomography: history, current status, and laboratory work. Invest Ophthalmol Vis Sci. 2011;52(5):2425-36.

81. Lee CS, Tyring AJ, Deruyter NP, Wu Y, Rokem A, Lee AY. Deep-learning based, automated segmentation of macular edema in optical coherence tomography. Biomed Opt Express. 2017;8(7):3440-8.

82. De Fauw J, Ledsam JR, Romera-Paredes B, Nikolov S, Tomasev N, Blackwell $\mathrm{S}$, et al. Clinically applicable deep learning for diagnosis and referral in retinal disease. Nat Med. 2018;24(9):1342-50

83. Xu Y, Yan K, Kim J, Wang X, Li C, Su L, et al. Dual-stage deep learning framework for pigment epithelium detachment segmentation in polypoidal choroidal vasculopathy. Biomed Opt Express. 2017:8(9):4061-76.

84. Memari N, Ramli AR, Bin Saripan MI, Mashohor S, Moghbel M. Supervised retinal vessel segmentation from color fundus images based on matched filtering and AdaBoost classifier. PLoS One. 2017;12(12):e0188939.

85. Venhuizen FG, van Ginneken B, Liefers B, van Asten F, Schreur V, Fauser S, et al. Deep learning approach for the detection and quantification of intraretinal cystoid fluid in multivendor optical coherence tomography. Biomed Opt Express. 2018;9(4):1545-69.

86. Bogunovic H, Waldstein SM, Schlegl T, Langs G, Sadeghipour A, Liu X, et al. Prediction of anti-vegf treatment requirements in neovascular amd using a machine learning approach. Invest Ophthalmol Vis Sci. 2017:58(7):3240-8.

87. Treder M, Lauermann JL, Eter N. Automated detection of exudative agerelated macular degeneration in spectral domain optical coherence tomography using deep learning. Graefes Arch Clin Exp Ophthalmol. 2018; 256(2):259-65.

88. Jonas JB, Budde WM, Panda-Jonas S. Ophthalmoscopic evaluation of the optic nerve head. Surv Ophthalmol. 1999;43(4):293-320.

89. Weinreb RN, Khaw PT. Primary open-angle glaucoma. Lancet. 2004; 363(9422):1711-20. 
90. Bizios D, Heijl A, Hougaard JL, Bengtsson B. Machine learning classifiers for glaucoma diagnosis based on classification of retinal nerve fibre layer thickness parameters measured by stratus OCT. Acta Ophthalmol. 2010;88(1):44-52.

91. Barella KA, Costa VP, Goncalves Vidotti V, Silva FR, Dias M, Gomi ES. Glaucoma diagnostic accuracy of machine learning classifiers using retinal nerve fiber layer and optic nerve data from SD-OCT. J Ophthalmol. 2013; 2013:789129.

92. Omodaka K, An G, Tsuda S, Shiga Y, Takada N, Kikawa T, et al. Classification of optic disc shape in glaucoma using machine learning based on quantified ocular parameters. PLoS One. 2017;12(12):e0190012.

93. Silver D, Huang A, Maddison CJ, Guez A, Sifre L, van den Driessche G, et al. Mastering the game of go with deep neural networks and tree search. Nature. 2016;529(7587):484-9.

94. EITanboly A, Ismail M, Shalaby A, Switala A, El-Baz A, Schaal S, et al. A computer-aided diagnostic system for detecting diabetic retinopathy in optical coherence tomography images. Med Phys. 2017;44(3):914-23.

95. Han T, Liu C, Yang W, Jiang D. Learning transferable features in deep convolutional neural networks for diagnosing unseen machine conditions. ISA Trans. 2019;93:341-53.

96. Kermany DS, Goldbaum M, Cai W, Valentim CCS, Liang H, Baxter SL, et al. Identifying medical diagnoses and treatable diseases by image-based deep learning. Cell. 2018;172(5):1122-31 e9.

97. Ong YT, Hilal S, Cheung CY, Venketasubramanian N, Niessen WJ, Vrooman $\mathrm{H}$, et al. Retinal neurodegeneration on optical coherence tomography and cerebral atrophy. Neurosci Lett. 2015;584:12-6.

98. Huang W, Chan KL, Li H, Lim JH, Liu J, Wong TY. A computer assisted method for nuclear cataract grading from slit-lamp images using ranking. IEEE Trans Med Imaging. 2011;30(1):94-107.

99. Fan S, Dyer CR, Hubbard L, Klein B. An Automatic System for Classification of Nuclear Sclerosis from Slit-Lamp Photographs. In: Medical Image Computing and Computer-Assisted Intervention - MICCAI, vol. 2003; 2003. p. 592-601.

100. Li H, Lim JH, Liu J, Mitchell P, Tan AG, Wang JJ, et al. A computer-aided diagnosis system of nuclear cataract. IEEE Trans Biomed Eng. 2010;57(7): 1690-8.

101. Lin D, Chen J, Lin Z, Li X, Wu X, Long E, et al. 10-year overview of the hospital-based prevalence and treatment of congenital cataracts: the CCPMOH experience. PLoS One. 2015;10(11):e0142298.

102. Wu X, Long E, Lin H, Liu Y. Prevalence and epidemiological characteristics of congenital cataract: a systematic review and meta-analysis. Sci Rep. 2016;6: 28564.

103. West SK, Rosenthal F, Newland HS, Taylor HR. Use of photographic techniques to grade nuclear cataracts. Invest Ophthalmol Vis Sci. 1988;29(1):73-7.

104. Amaya L, Taylor D, Russell-Eggitt I, Nischal KK, Lengyel D. The morphology and natural history of childhood cataracts. Surv Ophthalmol. 2003;48(2): 125-44.

105. Marc RE, Jones BW, Watt CB, Anderson JR, Sigulinsky C, Lauritzen S. Retinal connectomics: towards complete, accurate networks. Prog Retin Eye Res. 2013:37:141-62.

106. Jiang J, Liu X, Liu L, Wang S, Long E, Yang H, et al. Predicting the progression of ophthalmic disease based on slit-lamp images using a deep temporal sequence network. PLoS One. 2018;13(7):e0201142.

107. Liu X, Jiang J, Zhang K, Long E, Cui J, Zhu M, et al. Localization and diagnosis framework for pediatric cataracts based on slit-lamp images using deep features of a convolutional neural network. PLoS One. 2017;12(3):e0168606.

108. Long E, Lin H, Liu Z, Wu X, Wang L, Jiang J, et al. An artificial intelligence platform for the multihospital collaborative management of congenital cataracts. Nat Biomed Eng. 2017;1(2):0024.

109. Lin H, Long E, Chen W, Liu Y. Documenting rare disease data in China. Science. 2015;349(6252):1064

110. Wang L, Zhang K, Liu X, Long E, Jiang J, An Y, et al. Comparative analysis of image classification methods for automatic diagnosis of ophthalmic images. Sci Rep. 2017;7:41545.

111. Arcadu F, Benmansour F, Maunz A, Michon J, Haskova Z, McClintock D, et al. Deep learning predicts oct measures of diabetic macular thickening from color fundus photographs. Invest Ophthalmol Vis Sci. 2019;60(4):852-7.

112. Nagasawa T, Tabuchi H, Masumoto H, Enno H, Niki M, Ohara Z, et al. Accuracy of ultrawide-field fundus ophthalmoscopy-assisted deep learning for detecting treatment-naive proliferative diabetic retinopathy. Int Ophthalmol. 2019;39(10):2153-9.
113. Phan S, Satoh S, Yoda Y, Kashiwagi K, Oshika T. Japan ocular imaging registry research group. Evaluation of deep convolutional neural networks for glaucoma detection. Jpn J Ophthalmol. 2019;63(3):276-83.

114. Nagasato D, Tabuchi H, Ohsugi H, Masumoto H, Enno H, Ishitobi N, et al. Deep-learning classifier with ultrawide-field fundus ophthalmoscopy for detecting branch retinal vein occlusion. Int J Ophthalmol. 2019;12(1):94-9.

115. Burlina PM, Joshi N, Pacheco KD, Liu TYA, Bressler NM. Assessment of deep generative models for high-resolution synthetic retinal image generation of age-related macular degeneration. JAMA Ophthalmol. 2019;137(3):258-64.

116. Girard F, Kavalec C, Cheriet F. Joint segmentation and classification of retinal arteries/veins from fundus images. Artif Intell Med. 2019;94:96-109.

117. Coyner AS, Swan R, Brown JM, Kalpathy-Cramer J, Kim SJ, Campbell JP, et al. Deep learning for image quality assessment of fundus images in retinopathy of prematurity. AMIA Annu Symp Proc. 2018;2018:1224-32.

118. Keel S, Wu J, Lee PY, Scheetz J, He M. Visualizing deep learning models for the detection of referable diabetic retinopathy and glaucoma. JAMA Ophthalmol. 2019;137(3):288-92.

119. Sayres R, Taly A, Rahimy E, Blumer K, Coz D, Hammel N, et al. Using a deep learning algorithm and integrated gradients explanation to assist grading for diabetic retinopathy. Ophthalmology. 2019;126(4):552-64.

120. Peng Y, Dharssi S, Chen Q, Keenan TD, Agron E, Wong WT, et al. DeepSeeNet: a deep learning model for automated classification of patientbased age-related macular degeneration severity from color fundus photographs. Ophthalmology. 2019;126(4):565-75.

121. Guo Y, Budak U, Sengur A. A novel retinal vessel detection approach based on multiple deep convolution neural networks. Comput Methods Prog Biomed. 2018;167:43-8.

122. Khojasteh P, Aliahmad B, Kumar DK. Fundus images analysis using deep features for detection of exudates, hemorrhages and microaneurysms. BMC Ophthalmol. 2018;18(1):288.

123. Gargeya R, Leng T. Automated identification of diabetic retinopathy using deep learning. Ophthalmology. 2017;124(7):962-9.

124. Ordonez PF, Cepeda CM, Garrido J, Chakravarty S. Classification of images based on small local features: a case applied to microaneurysms in fundus retina images. J Med Imaging (Bellingham). 2017;4(4):041309.

125. Abbas Q, Fondon I, Sarmiento A, Jimenez S, Alemany P. Automatic recognition of severity level for diagnosis of diabetic retinopathy using deep visual features. Med Biol Eng Comput. 2017;55(11):1959-74.

126. Pfister M, Schutzenberger K, Pfeiffenberger U, Messner A, Chen Z, Dos Santos VA, et al. Automated segmentation of dermal fillers in OCT images of mice using convolutional neural networks. Biomed Opt Express. 2019; 10(3):1315-28.

127. Fu H, Baskaran M, Xu Y, Lin S, Kee Wong DW, Liu J, et al. A deep learning system for automated angle-closure detection in anterior segment optical coherence tomography images. Am J Ophthalmol. 2019;203:37-45.

128. Masood S, Fang R, Li P, Li H, Sheng B, Mathavan A, et al. Automatic choroid layer segmentation from optical coherence tomography images using deep learning. Sci Rep. 2019;9(1):3058.

129. Dos Santos VA, Schmetterer L, Stegmann H, Pfister M, Messner A, Schmidinger G, et al. CorneaNet: fast segmentation of cornea OCT scans of healthy and keratoconic eyes using deep learning. Biomed Opt Express. 2019;10(2):622-41.

130. Asaoka R, Murata H, Hirasawa K, Fujino Y, Matsuura M, Miki A, et al. Using deep learning and transfer learning to accurately diagnose early-onset glaucoma from macular optical coherence tomography images. Am J Ophthalmol. 2019;198:136-45.

131. Lu W, Tong Y, Yu Y, Xing Y, Chen C, Shen Y. Deep learning-based automated classification of multi-categorical abnormalities from optical coherence tomography images. Transl Vis Sci Technol. 2018;7(6):41.

132. Schlegl T, Waldstein SM, Bogunovic H, Endstrasser F, Sadeghipour A, Philip AM, et al. Fully automated detection and quantification of macular fluid in oct using deep learning. Ophthalmology. 2018;125(4):549-58.

133. Prahs P, Radeck V, Mayer C, Cvetkov Y, Cvetkova N, Helbig H, et al. OCTbased deep learning algorithm for the evaluation of treatment indication with anti-vascular endothelial growth factor medications. Graefes Arch Clin Exp Ophthalmol. 2018;256(1):91-8.

134. Shah A, Zhou L, Abramoff MD, Wu X. Multiple surface segmentation using convolution neural nets: application to retinal layer segmentation in OCT images. Biomed Opt Express. 2018;9(9):4509-26.

135. Chan GCY, Kamble R, Muller H, Shah SAA, Tang TB, Meriaudeau F. Fusing results of several deep learning architectures for automatic classification of 
normal and diabetic macular edema in optical coherence tomography. Conf Proc IEEE Eng Med Biol Soc. 2018;2018:670-3.

136. Muhammad H, Fuchs TJ, De Cuir N, De Moraes CG, Blumberg DM, Liebmann JM, et al. Hybrid deep learning on single wide-field optical coherence tomography scans accurately classifies glaucoma suspects. J Glaucoma. 2017;26(12):1086-94.

137. Lee CS, Baughman DM, Lee AY. Deep learning is effective for the classification of OCT images of normal versus age-related macular degeneration. Ophthalmol Retina. 2017;1(4):322-7.

138. Bengio Y, Courville A, Vincent P. Representation Learning: A review and new perspectives. IEEE Trans Pattern Analysis Machine Int. 2013;35(8):1798-828.

139. Chiang MF, Erdogmus D, Keck K, You S, Kalpathy-Cramer J, Ataer-Cansizoglu E. Analysis of underlying causes of inter-expert disagreement in retinopathy of prematurity diagnosis. Methods Inf Med. 2018;54(1):93-102.

Ready to submit your research? Choose BMC and benefit from:

- fast, convenient online submission

- thorough peer review by experienced researchers in your field

- rapid publication on acceptance

- support for research data, including large and complex data types

- gold Open Access which fosters wider collaboration and increased citations

- maximum visibility for your research: over $100 \mathrm{M}$ website views per year

At $\mathrm{BMC}$, research is always in progress.

Learn more biomedcentral.com/submissions 